\title{
A Statistical Evaluation Model for Driver-Bus-Route Combinatorial Optimization
}

\author{
Denggao Huang ${ }^{1 \dagger}$, Hui Xie ${ }^{1}$, Qiang Sun ${ }^{1}$, Hongjie Ma ${ }^{1}$, Tielong Shen ${ }^{2}$ \\ 1.State key laboratory of engines, Tianjin University, Tianjin, China \\ (Tel: +86-022-2740-7723; E-mail: xiehui@tju.edu.cn) \\ 2. Department of Engineering and Applied Sciences, Sophia University, Tokyo 102-8554, Japan \\ (E-mail: tetu-sin@sophia.ac.jp)
}

\begin{abstract}
Bus fuel economy is closely related to driver's habits and driving conditions. How to efficiently arrange drivers, buses and routes with better fuel economy is a difficult problem for bus companies. This paper aims to propose a statistical evaluation model for this problem. The features of bus configurations, driver operations and driving routes were analyzed, and 6 key factors were defined to represent their effects on fuel economy, which are bus design optimal velocity, bus design optimal acceleration, driver desiring velocity, driver desiring acceleration, mean velocity of bus route and mean acceleration of bus route. Based on the power balance of driver-bus-route, the problem of driverbus-route optimization can be depicted by driver, bus and route statistical points. The sum of weighted distance of three points can be set as the evaluation index of driver-bus-route arrangement. This statistical valuation model was finally applied with the monitor data from 11 drivers, 2 bus lines and 2 typical buses for more than one year. The data analysis results show that the sorting result of evaluation index is consistent with fuel economy and the proposed evaluation index can effective predict the fuel economy level of driver-bus-route arrangement. By comparing the evaluation index of the statistical evaluation model, a relatively optimal arrangement of bus-driver-routes for fuel saving can be achieved.
\end{abstract}

Keywords: Driver-bus-route, city bus, arrangement, optimization

\section{INTRODUCTION}

Energy consumption of a city bus depends on various physical factors, such as characteristics of its engine, the powertrain system, the structure of bus against aerodynamic drag, road surface conditions, and the weather. Besides these factors, driving behaviors and driving conditions also have a great influence on fuel consumption. Driving behavior differences can contribute, in total, to about $45 \%$ reduction of the on-road fuel economy [1]. The vehicle fuel economy and emission are also deeply affected by driving condition. Therefore, how to efficiently arrange vehicle fleet and drivers with better fuel economy is a difficult issue. The issue is very important for bus companies and often solved by the manager's experience. A statistical valuation model is proposed to solve this issue, based the relations of driver-bus-route.

The issues of optimal arrangement of buses, drivers and routes can be summarized as two points: 1) Abstracting main factors of driver-bus-route relative to bus fuel economy; 2) Developing an evaluation model to assess their influence and giving advices for better arrangement of buses, drivers and routes. The driver-bus-road factors affecting on fuel economy are mostly illustrated by Ericson [2-4]. Ericson abstracted 16 characters to describe fuel sensitive factors from drivers, driver operations, road types and vehicle types, and intended to give an influence scope of street characteristics, driver categories and car performance. In the field of driver-bus-route matching evaluation model(DBRME), Zhu W. developed a model framework for the independent measurement of bus operating efficiency and quality of bus service to analyze the effects of external operating environment on the performance of bus routes [5] .Barnum, D. used Data
Envelopment Analysis scores to account for the environmental influences [6].Furthermore, Site P. D. proposed a formulations model of optimal bus service in urban areas, considering service level, price and bus size, with fuel saving objective and various financial constraints [7]. Yu, Bina set up a model for optimizing bus route headway by parallel genetic algorithm, aiming to find an acceptable balance between passenger costs and operator costs, namely the maximization of service quality and the minimization of operational costs [8].

This paper aims to abstract a series of statistical parameters to represent features of drivers, buses and routes. An evaluation index of driver-bus-route is proposed for efficient arrangements, based on Matching Rule of Driver-Bus-Route (MRDBR). With the Matching Rule of Driver-Bus-Route, the driver can steer bus at its optimal efficient working surfaces, and be subjected to driving cycle of bus route.

This paper is organized as follows. In section 2 , the features of driver, bus and route are defined based on bus kinematical formulation and driver-bus-route evaluation index for efficient arrangement is proposed. This method is applied to driver-bus-route arrangement evaluation of two bus line in section 3 . The advantages and drawbacks of this method are discussed in section 4 . Conclusions are made in section 5.

\section{METHODOLOGY}

\subsection{Factors affecting bus fuel economy}

The bus running resistance consists of 4 forces: rolling resistance, aerodynamic resistance, grade resistance, and inertia resistance. The bus dynamical resistance force is as following Eq. (1).

$$
F_{f}=m g f \cos \theta+\frac{C_{d} A v^{2}}{21.15}+m g \sin \theta+m a
$$

\footnotetext{
$\uparrow$ Denggao Huang is the presenter of this paper. This work was supported by the International Science and Technology Cooperation Program of China (2013DFG62890) and the National Nature Science Foundation of China (51307119).
} 
Where $C_{d}, A, f, m, g$ and $\theta$ are air drag coefficient, frontal area of bus, rolling resistance coefficient, mass, gravity and the road grade, respectively. $a, v$ are bus acceleration $\left(\mathrm{m} / \mathrm{s}^{2}\right)$ and velocity $(\mathrm{km} / \mathrm{h})$ respectively.

The traction force is related by transmission ratio and engine brake torque, as Eq. (2).

$$
\mathrm{F}_{\mathrm{d}}=\mathrm{T}_{\mathrm{e}} \mathrm{i}_{0} \mathrm{i}_{\mathrm{g}} \mathrm{D}_{\mathrm{c}} / \mathrm{R}
$$

Where $F_{d}, T_{e}, R, i_{0}, i_{g}$ are tire driving force $(\mathrm{N})$, engine brake torque $(\mathrm{Nm})$, wheel $\operatorname{radius}(\mathrm{m})$, main ratio and gearbox ratio, respectively. $D_{c}$ is the state of clutch, when the clutch is engaged, $D_{c}=1$, and when the bus is in neutral and declutched, $D_{c}=0$. Based on bus kinematic dynamic, the relation between bus velocity and engine speed is shown in Eq. (3).

$$
\mathrm{N}_{\mathrm{e}}=\frac{v}{2 \pi \mathrm{R}} \mathrm{i}_{0} \mathrm{i}_{\mathrm{g}} \mathrm{D}_{\mathrm{c}}
$$

Based on the control map of fuel injection in engine control unit, the mass flow of diesel engine is determined by brake torque and the engine speed (rpm). Engine fuel consumption model can be depicted as Eq. (4) and Eq. (5). Where $\mathrm{T}_{\mathrm{e}}, \mathrm{N}_{\mathrm{e}}, \mathrm{P}_{\mathrm{e}}, \dot{\mathrm{P}_{\mathrm{e}}}$ are engine brake torque $(\mathrm{Nm})$, engine speed(rpm), output power of engine $(\mathrm{Kw})$ and change rate of output power. $\mathrm{C}_{\mathrm{i}}, \mathrm{k}_{2}$ and $\mathrm{k}_{1}$ are coefficients. $\mathrm{Q}_{\mathrm{FE}}(\mathrm{kg} / \mathrm{h})$ is the fuel consumption under transient operating conditions of engine.

$$
\begin{aligned}
& \mathrm{Q}_{\mathrm{FE}}=\sum_{\mathrm{i}=0}^{3} \mathrm{C}_{\mathrm{i}}\left(1+\mathrm{k}_{1} \dot{\mathrm{P}}_{\mathrm{e}}^{2}\right) \mathrm{P}_{\mathrm{e}}^{\mathrm{i}} \\
& \mathrm{P}_{\mathrm{e}}=\mathrm{k}_{2} \mathrm{~N}_{\mathrm{e}} \mathrm{T}_{\mathrm{e}}
\end{aligned}
$$

Based on the control strategy of driving operations in an electronic control unit (ECU), the output torque of engine is determined by the engine speed $\mathrm{N}_{\mathrm{e}}$ and the depth of accelerator pedal $\mathrm{A}(\%)$.

$$
\mathrm{T}_{\mathrm{e}}=\sum_{\mathrm{i}+\mathrm{j}=0}^{3} \mathrm{k}_{(\mathrm{i}, \mathrm{j})} \mathrm{N}_{\mathrm{e}}^{\mathrm{i}} \mathrm{A}^{\mathrm{j}}
$$

Based on Eq. (3) to (6), the bus transient fuel economy model can be summarized as Eq. (7).

$$
\mathrm{Q}_{\mathrm{FE}}=\mathrm{f}\left(\mathrm{A}, \mathrm{v}, \frac{\mathrm{dA}}{\mathrm{dt}}, \frac{\mathrm{dv}}{\mathrm{dt}}, \mathrm{i}_{\mathrm{g}}\right)
$$

In Eq. (7), accelerator pedal percentage (A), acceleration pedal changing rate $(d A / d t)$, gear selection $\left(i_{g}\right)$, driving speed $(v)$ and driving acceleration $(d v / d t)$ are the key factors for bus fuel economy. They can be used as reference features of bus configuration, driver operation and driving route.

\subsection{Features abstration of driver-bus-route system \\ 2.2.1 Description of driver features}

Based on Eq. (7), Accelerator pedal percentage, accelerator pedal changing rate and gear selection are the driver decision outputs. Gear selection and shift time are usually determined by powertrain configuration. With the development of auto manual transmission technology, gear selection is less influenced by driver habits. Accelerator pedal percentage and accelerator pedal changing rate are the representations of driver's demand of driving speed and acceleration [9]. They are closely related to the driver habits and fuel consumption. The probability density functions of accelerator pedal percentage and changing rate are calculated to represent driver demand habits. The process methods are shown in Eq. (8) and Eq. (9).

$$
\begin{aligned}
& y_{d \_a c c p e d a l}=f(A), v \in[0,100] \\
& y_{d \_a c c r a t e}=f\left(\frac{d A}{d t}\right), A \in[0,100]
\end{aligned}
$$

Where, $y_{d_{-} \text {accpedal }}, y_{d_{-} \text {accrate }}$ are the probability density of accelerator pedal percentage and changing rate.

The drivers often adjust pedal depth and changing rate to follow front vehicles[10].A linear model is proposed to describe the relation between (Accelerator pedal percentages, accelerator pedal changing rate) and (desiring speed, desiring acceleration). The relations are following Eq. (10) and Eq. (12).

$$
\begin{aligned}
& V_{\text {driver }}=K 1 \times A \\
& \text { Acc }_{\text {driver }}=K 2 \times \frac{d A}{d t}
\end{aligned}
$$

Where, $V_{\text {driver }}$ represents driver desired speed $(\mathrm{km} / \mathrm{h})$, Acc $_{\text {driver }}$ represents bus acceleration expected by driver accelerator pedal changing rate $\left(\mathrm{m} / \mathrm{s}^{2}\right) . K 1$ and $K 2$ are defined as transform coefficient here $(\mathrm{km} / \%)$, and calculated by empirical dataset.

Based on the Eq. (8) to Eq. (11), the probability density functions of desired speed and acceleration are calculated as Eq. (12) and Eq. (13).

$$
\begin{aligned}
& y_{v_{-} \text {driver }}=K 1 \times f(A), v \in[0,100] \\
& y_{v_{-} \text {acc }}=K 2 \times f\left(\frac{d A}{d t}\right), A \in[0,100]
\end{aligned}
$$

Where, $y_{v_{-} \text {driver }}$ and $y_{v_{-} a c c}$ are the probability density of driver desired speed and acceleration.

2.2.2 Description of bus optimal features

For bus powertrain system, there are optimal design running speed and acceleration curves. The solving equations are shown as Eq. (14) below.

$$
\begin{aligned}
& \left(V_{\text {veh_opti }}, a_{\text {veh_opti }}\right)= \\
& \underbrace{\min }_{\text {fuel economy }}\left\{F\left(B S F C, f_{r}, R, i_{g}\right)\right\}
\end{aligned}
$$

Where, $V_{\text {veh_opti }}, A c c_{\text {veh_opti }}$ are bus optimal design speed $(\mathrm{km} / \mathrm{h})$ and optimal design acceleration $\left(\mathrm{m} / \mathrm{s}^{2}\right)$, BSFC is engine universal characteristic $(\mathrm{g} /(\mathrm{kw} \cdot \mathrm{h})), f_{r}, R, i_{g}$ denote the rolling resistance of bus rolling resistance coefficient, tire radius and gears. The bus economy working point 'of $\left(V_{\text {veh_opti }}, A c c_{\text {veh_opti }}\right)$ is attributed to bus feature.

\subsubsection{Description of route driving cycle feature}

Bus speed and acceleration is the power demand of driving cycle, so the main features of bus route are the distributions of speed and acceleration [11]. Statistical distribution density of speed and acceleration for bus lines can be calculated as Eq. (15) to (16).

$$
y_{v_{-} \text {route }}=f(v), v \in[0,70]
$$




$$
y_{a_{-} \text {route }}=f\left(\frac{d v}{d t}\right), \mathrm{v} \in[0,70]
$$

Where, $y_{v_{-} \text {route }}$ is the probability density of route speed $v(\mathrm{~km} / \mathrm{h}), y_{\text {a route }}$ is probability density of acceleration $a\left(\mathrm{~m} / \mathrm{s}^{2}\right)$.

\subsection{Method of constructing statistical model}

The distributions of accelerator pedal percentage and changing rate represent driver power. Bus design optimal speed-acceleration is the efficient output power of bus working point. The product of speed and acceleration is the basic driving power demand management for route driving cycle. The power character relations between driver-bus-route are shown in the Fig.(1). The black filled areas of Fig.(1) is the efficient arrangements, in which drivers can steer bus at its optimal efficient working points, and be subjected to driving cycle of bus route.

Based on driver-bus-route distribution characters, the efficient match arrangement of drivers, buses and routes, is a multi-distribution matching problem of drivers, buses and routes.

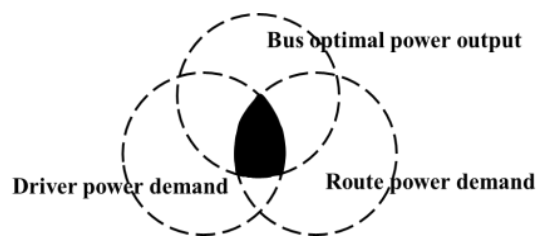

Fig. 1 Power relations of driver-bus-route system

The basic principles of statistics illustrate that statistical mean value is consistent with the characteristics of statistical distribution. Therefore, the multi-distribution features matching problem can be simplified to statistical mean values matching problem. Schematic of efficient match arrangements is shown in figure 2 .

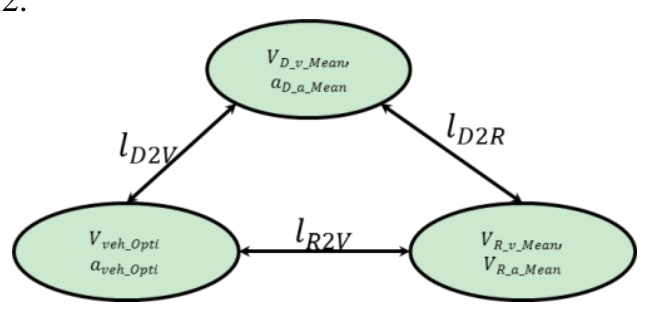

Fig.2 Matching triangle of driver-bus-route

Based on the Eq.(12), Eq.(13), Eq.(15) and Eq.(16), the calculations of statistical mean values are as following Eq. (17) to Eq. (20).

$$
\begin{aligned}
& \mathrm{V}_{\mathrm{D}_{-} V_{-} \text {Mean }}=\int_{0}^{100} \mathrm{~K} 1^{2} \times \mathrm{A} \times \mathrm{f}(\mathrm{A}) \mathrm{dA} \\
& a_{D_{-} a \_ \text {Mean }}=\int_{0}^{100} K 2^{2} \times \frac{d A}{d t} \times f\left(\frac{d A}{d t}\right) d\left(\frac{d A}{d t}\right) \\
& V_{R_{-} v_{-} \text {Mean }}=\int_{0}^{70} v f(v) d v, v \in(0,70] \\
& a_{R_{-} \text {a_Mean }}=\int_{0}^{70}\left(\frac{d v}{d t}\right) f\left(\frac{d v}{d t}\right) d\left(\frac{d v}{d t}\right), v \in(0,70]
\end{aligned}
$$

Where, $V_{D_{-} v_{-} \text {Mean }}, a_{D_{\_} a_{-} \text {Mean }}$ are feature parameters of driver (desired speed $(\mathrm{km} / \mathrm{h})$, desired acceleration $(\mathrm{m} /$ $\left.\left.s^{2}\right)\right), V_{R_{-} v_{-} \text {Mean }}, V_{R_{-} a \_ \text {Mean }}$ are feature parameters of route driving cycle (average speed $(\mathrm{km} / \mathrm{h}$ ), average acceleration $\left.\left(\mathrm{m} / \mathrm{s}^{2}\right)\right)$.Particularly, city bus idling stop condition is not included, in which bus fuel consumption is often constant. Impact of transit vehicle brake pedal kinetic energy loss is not considered, because the proportion of fuel consumption is relatively small and above $50 \%$ energy is consumed during the acceleration of a city bus [12].

In which, $l_{D 2 V}, l_{R 2 V}, l_{D 2 R}$ are defined as evaluation index of Driver-Bus, Route-Driver, Driver-Route. The calculation equation of $l_{D 2 V}, l_{R 2 V}, l_{D 2 R}$ are shown in Eq.(21), $\mathrm{Eq}(22), \mathrm{Eq}(23)$. If the value of evaluation index is small, the components of driver-bus-route are better matched.

$$
\begin{aligned}
& \mathrm{l}_{\text {D2V }}= \\
& \sqrt[2]{\left(\mathrm{V}_{\text {D_v_Mean }}-\mathrm{V}_{\text {veh_Opti }}\right)^{2}+\left(\mathrm{a}_{\text {D_a_Mean }}-\mathrm{a}_{\text {veh_Opti }}\right)^{2}}
\end{aligned}
$$

$$
\begin{aligned}
& \mathrm{l}_{\mathrm{R} 2 \mathrm{~V}}= \\
& \sqrt[2]{\left(\mathrm{V}_{\mathrm{R} \_\mathrm{V} \_ \text {Mean }}-\mathrm{V}_{\mathrm{veh} \_ \text {Opti }}\right)^{2}+\left(\mathrm{a}_{\mathrm{R} \_\mathrm{a} \_ \text {Mean }}-\mathrm{a}_{\mathrm{veh} \_ \text {Opti }}\right)^{2}}
\end{aligned}
$$

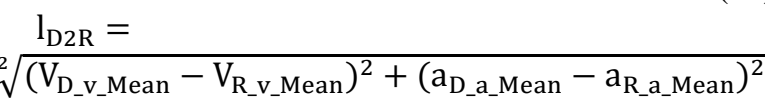

Based on the matching rule (MRDBR), the sum of weighted distance between driver, bus and route can be calculated as Eq. (24).

$$
\mathrm{l}_{\mathrm{D}_{-} \mathrm{V}_{-} \mathrm{R}}=\alpha \mathrm{l}_{\mathrm{D} 2 \mathrm{~V}}+\beta \mathrm{l}_{\mathrm{R} 2 \mathrm{~V}}+\gamma \mathrm{l}_{\mathrm{D} 2 \mathrm{R}}(\alpha, \beta, \gamma>0)
$$

Where, $\alpha, \beta, \gamma$ are the weighting coefficients for driver-bus-route matching, and can be calibrated by experimental data. $l_{D_{-} V_{-} R}$ represents evaluation index of driver-bus-route arrangement. When $l_{D_{-} V_{-} R}$ is small, the better arrangements of driver-bus-route.

The coefficients can be calculated by the rank of driver-bus-route matching and fuel economy, as shown in Eq. (25). The coefficients are given by maximum $\mathrm{R}$ returned.

$$
\begin{aligned}
& \{\mathrm{K} 1, \mathrm{~K} 2, \alpha, \beta, \gamma\}=\underbrace{\max }_{R}\{R \mid R=1- \\
& \left.6 \frac{\sum\left(\mathrm{l}_{D_{-} V_{-} R}(i)-F(i)\right)^{2}}{N(N-1)}\right\} \mathrm{i}=1,2,3, \sim, \mathrm{N}
\end{aligned}
$$

Where, $\mathrm{R}$ is the spearman coefficient between the estimated evaluation index and fuel economy of special driver-bus-route. $\mathrm{l}_{D_{-} V_{-} R}(i)$ is the estimated evaluation index of the $\mathrm{i}_{\text {th }}$ driver-bus-route system. $F(i)$ is experimental fuel economy of the $i_{\text {th }}$ driver-bus-route system. $\mathrm{N}$ is the simple number of driver-bus-route system.

\section{APPLICATION AND RESULTS}

To validate the proposed evaluation index $\left(l_{D_{-} V_{-} R}\right)$, the actual operating data of Tianjin bus line 503, 516 were been acquired by public transportation vehicles OBD port. The acquisition data is more than 14600 cycles, covering four season of whole year.

The database includes six buses, 11 drivers with fuel 
consumption, speed, pedal operation, gear, GPS and other information, which are recorded at a frequency of $10 \mathrm{~Hz}$ in SD card, meeting the accuracy requirements. The bus configurations are as follow table.

Table 1 Configuration of monitoring bus

\begin{tabular}{|l|l|l|}
\hline & 503 line & 516 line \\
\hline Bus type & YUT ZK6902HGA & SLK6905UF5 \\
\hline Engine & YC6J200-30 & YC6J200-30 \\
\hline Gearbox & $1 / 2 / 3 / 4 / 5$ & $1 / 2 / 3 / 4 / 5$ \\
Ratio & $6.9 / 4.13 / 2.45 / 1.49 / 1$ & $8.3 / 4.8 / 2.9 / 1.76 / 1]$ \\
\hline Main ratio & 5.571 & 3.75 \\
\hline Tire radius & $0.53975 \mathrm{~m}$ & $0.469 \mathrm{~m}$ \\
\hline Roll coef. & 0.0062551 & 0.0062551 \\
\hline Air coef. & 0.67349 & 0.67349 \\
\hline Front area & $7.7924 \mathrm{~m}^{2}$ & $7.84 \mathrm{~m}^{2}$ \\
\hline Drivers & 6 drivers & 5 drivers \\
\hline
\end{tabular}

503 line dataset was used to calibrate driver-bus-route statistical coefficients. 516 line dataset was used to validate the model prediction results. The results include feature analysis of bus, route driving cycle and driver pedal operations, and relations between distributions and statistical mean points of driver-bus-route system. Finally, the sorting result of evaluation index was evaluated.

\subsection{Driver-bus-route features of 503\&516line}

\subsubsection{Design optimal characteristics of city bus}

Based on the bus mechanical design, the fuel economy features are showed in Fig. 3 and Fig.4.

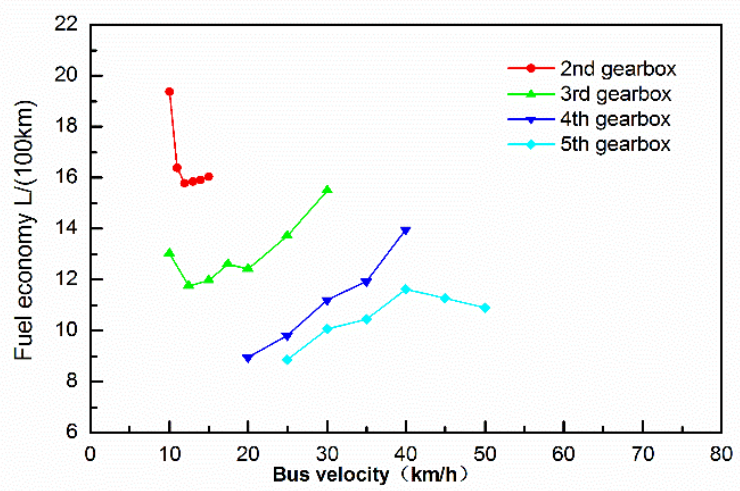

Fig.3 line 503 bus fuel economy feature

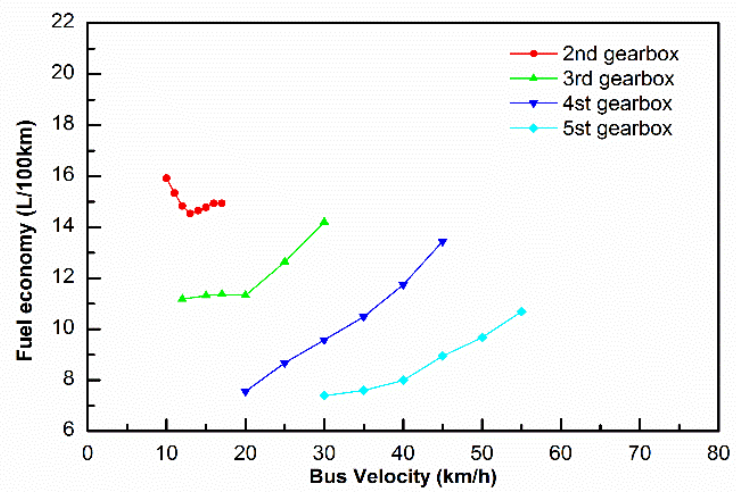

Fig. 4 line 516 bus fuel economy feature
The fuel consumption increased as the bus cruising speed increased. It can be inferred from[13] that, the increased vehicle acceleration led to increased fuel consumption. Therefore, the efficient state of city buses is cruising at its' optimal design velocity, and acceleration is zero. For the 503 line buses, the best economy working point is velocity at $20 \mathrm{~km} / \mathrm{h}$ and $4^{\text {th }}$ gearbox.For the 516 bus, the best economy working point is velocity at $21 \mathrm{~km} / \mathrm{h}$ and $4^{\text {th }}$ gearbox.

\subsubsection{Bus routes driving cycle features}

For city bus line, the driving cycle reflects profile of route traffic conditions. The distributions of velocity and acceleration for $503 \& 516$ bus route are shown in Fig. 5 and Fig. 6.

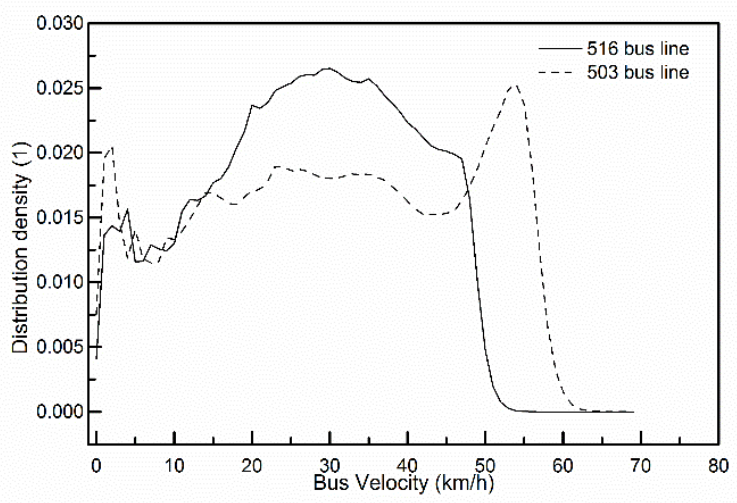

Fig. 5 Velocity density of $503 \& 516$ bus line

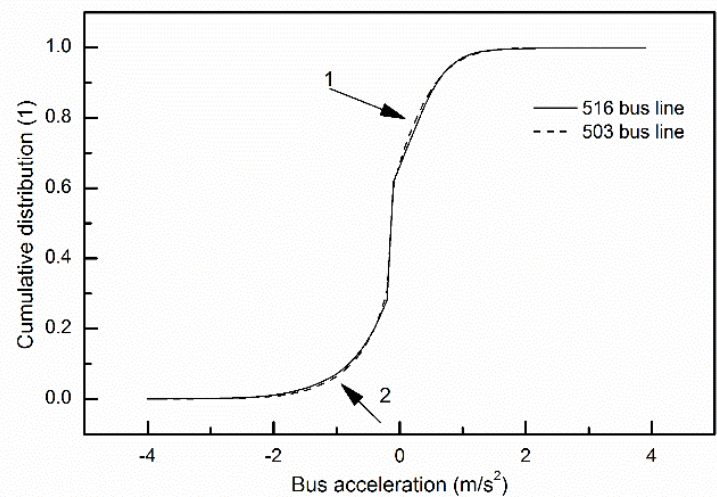

Fig. 6 Cumulative density of acceleration for $503 \& 516$

For bus line 503, it includes three territories, which are urban route, rapidway route and suburban route. The velocity density and cumulative density show three peaks. The first peak is bus velocity below $10 \mathrm{~km} / \mathrm{h}$, which represents urban driving cycle. The second peak is bus velocity between $10 \mathrm{~km} / \mathrm{h}$ and $45 \mathrm{~km} / \mathrm{h}$, which represents suburban driving cycle. The third peak is bus velocity between $45 \mathrm{~km} / \mathrm{h}$ and $70 \mathrm{~km} / \mathrm{h}$, which represents rapidway driving cycle. Compared to velocity frequency of 503 line, 516 line is a typical suburban route. $67 \%$ of cumulative density of acceleration of 503 line and 516 line is below zero, which means that buses spend more time in deceleration.

Statistical average route speed and acceleration of 
503 line are $31 \mathrm{~km} / \mathrm{h}$ and $0.41 \mathrm{~m} / \mathrm{s}^{2}$. Statistical average route speed and acceleration of 516 line are $27 \mathrm{~km} / \mathrm{h}$ and $0.4 \mathrm{~m} / \mathrm{s}^{2}$. As the arrow symbols 1 and 2 shown in figure 6 , the driving cycle of 503 line is more aggressive than 516 line.

\subsubsection{Driver pedal operation features}

As statistics and analysis of data sets, frequency statistical data of drivers' Acceleration pedal are shown in Fig. 7 and Fig. 8 for line 503 \&516. With the same route and type of bus, the distribution of accelerator position is totally different. With low acceleration pedal and smoothly acceleration operation, drivers tend to be lower fuel consumption[14]. 503Driver3 and 516Driver3 respectively have the most steep cumulative distribution line, which indicate that they will get much better fuel economy than other drivers . However, the accelerator pedal changing rate presents less difference for different drivers.
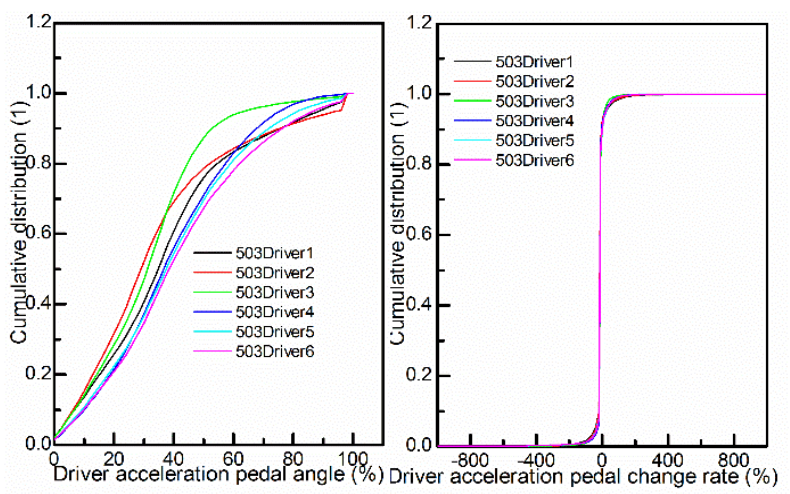

Fig. 7Cumulative distribution of accelerator position and accelerator pedal changing rate for line 503
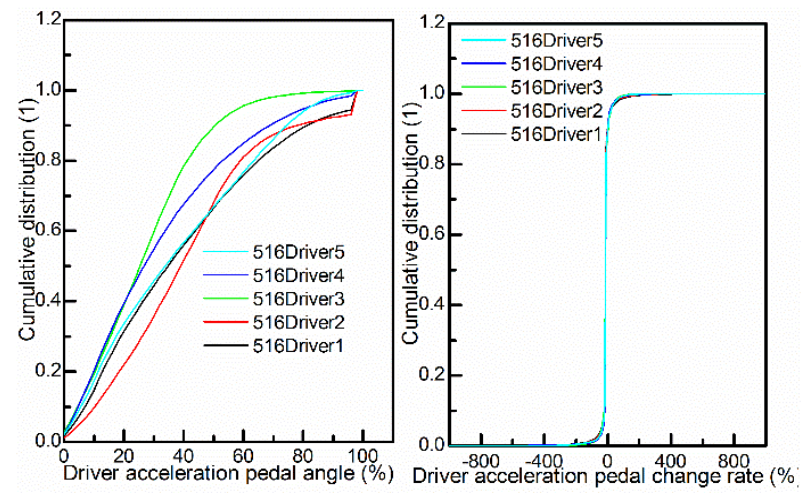

Fig. 8Cumulative distribution of accelerator position and accelerator pedal changing rate for line516

\subsection{Driver-bus-route evaluation index of $503 \& 516$}

3.2.1 Parameters calibration of Driver-bus-route evaluation model from data of line $\mathbf{5 0 3}$

From the theories of section 2 and Eq.(25), there are 5 parameters required to calibration by experimental data, which are $\mathrm{K} 1, \mathrm{~K} 2, \alpha, \beta, \gamma$. More than 20 bus routing rounds data are processed by each driver to reduce random errors. When Spearman correlation $(\mathrm{R})$ is equal to the maximum 1 from fuel economy rank of 6 drivers of 503 line, the returned values of $[\mathrm{K} 1, \mathrm{~K} 2, \alpha, \beta, \gamma]$ are $[1,1 / 35,1,1,1]$, calculated by the Eq.(25).The calculation results are shown in table 3 . The driver-bus matching index $\left(l_{\mathrm{D} 2 \mathrm{~V}}\right)$, driver-route evaluation index $\left(\mathrm{l}_{\mathrm{D} 2 \mathrm{R}}\right)$ and bus-route evaluation index $\left(\mathrm{l}_{\mathrm{V} 2 \mathrm{R}}\right)$ are also spearman correlated with fuel economy.

Meanwhile, the driver desiring speed and acceleration are listed in table 2 for line 503. The rank of driver desiring speed $\left(\mathrm{V}_{\text {D_v_Mean }}\right)$ and acceleration $\left(a_{D \_a \_M e a n}\right)$ are consistent with the ramps in Fig.7 and Fig. 8.

Table 2 Desiring speed and acceleration of line 503

\begin{tabular}{|c|c|c|c|}
\hline Driver No. & Size & $\begin{array}{c}\mathrm{V}_{\text {D_v_Mean }} \\
\mathrm{Km} / \mathrm{h}\end{array}$ & $\begin{array}{c}\mathrm{a}_{\text {D_a_Mean }} \\
\mathrm{m} / \mathrm{s}^{2}\end{array}$ \\
\hline 503Driver 1 & 73 & 38.31 & 0.55 \\
\hline 503Driver 2 & 110 & 35.42 & 0.49 \\
\hline 503Driver 3 & 146 & 32.32 & 0.41 \\
\hline 503Driver 4 & 21 & 39.22 & 0.46 \\
\hline 503Driver 5 & 27 & 40.32 & 0.48 \\
\hline 503Driver 6 & 40 & 42.10 & 0.48 \\
\hline
\end{tabular}

Table 3 Driver-bus-route evaluation index for line 503

\begin{tabular}{|l|l|l|l|l|l|l|}
\hline Driver No. & Size & $\begin{array}{c}\text { Fuel } \\
\text { L/100k } \\
\mathrm{m}\end{array}$ & $\mathrm{l}_{\mathrm{D}_{\mathrm{V}} \mathrm{V} \mathrm{R}}$ & $\mathrm{l}_{\mathrm{D} 2 \mathrm{R}}$ & $\mathrm{l}_{\mathrm{D} 2 \mathrm{~V}}$ & $\mathrm{l}_{\mathrm{V} 2 \mathrm{R}}$ \\
\hline 503Driver3 & 146 & 21.04 & 16.7 & 1.7 & 8.3 & 6.6 \\
\hline 503Driver2 & 110 & 21.12 & 22.9 & 4.8 & 11.4 & 6.6 \\
\hline 503Driver1 & 73 & 21.85 & 28.7 & 7.7 & 14.3 & 6.6 \\
\hline 503Driver4 & 21 & 23.57 & 30.5 & 8.6 & 15.2 & 6.6 \\
\hline 503Driver5 & 27 & 23.71 & 32.7 & 9.7 & 16.3 & 6.6 \\
\hline 503Driver6 & 40 & 24.62 & 36.2 & 11 & 18.1 & 6.6 \\
\hline \multicolumn{2}{|l|}{ Spearman correlation } & 1 & 1 & 1 & - \\
\hline
\end{tabular}

\subsubsection{Prediction of driver-bus-route evaluation index for} 516line

Based on the calibrated parameters [K1, K2, $\alpha, \beta, \gamma]$, the driver desiring speed and acceleration of line 516 are shown in table 4 . The Driver-bus-route evaluation index of 516 line for all drivers are listed in table 5.

From the results of table 4 and table 5, the Spearman correlation between the estimated evaluation index $\left(\mathrm{l}_{D_{-} V_{-} R}\right)$ and fuel economy (Fuel, L/100km) of special driver-bus-route is 1 . It reveals that this driver-bus-route evaluation index can be used as arrangement evaluation of drivers, buses and routes. The larger evaluation index $\mathrm{l}_{\mathrm{D} \text { V R }}$ yields higher fuel consumption, and vise versa. For evaluation index of driver-bus and driver-route, the rank of $l_{D 2 R}$ and $l_{D 2 V}$ is also useful.

Besides, the fuel economy of line 503 and line 516 is respectively $28 \mathrm{~km} / \mathrm{h}$ and $32 \mathrm{~L} / 100 \mathrm{~km}$ in experimental database. The $l_{\mathrm{V} 2 \mathrm{R}}$ of 503 line is smaller thant 516 line. It means that the bus and route is relatively better arranged in line 503 than line 516.

Table 4 Desiring speed and acceleration of line 516

\begin{tabular}{|l|l|l|l|}
\hline \multicolumn{1}{|c|}{ Driver No. } & Size & \begin{tabular}{c}
$\mathbf{V}_{\mathbf{D}_{\text {_v_Mean }}} \mathrm{Km} / \mathrm{h}$ \\
\hline 516Driver1
\end{tabular} & $\begin{array}{c}\boldsymbol{a}_{\boldsymbol{D} \_ \text {a_Mean }} \\
\mathrm{m} / \mathrm{s}^{2}\end{array}$ \\
\hline 516Driver2 & 128 & 40.40 & 0.53 \\
\hline 516Driver3 & 108 & 42.22 & 0.49 \\
\hline 516Driver4 & 128 & 27.87 & 0.45 \\
\hline 516Driver5 & 196 & 38.06 & 0.45 \\
\hline
\end{tabular}


Table 5 Estimated Driver-bus-route evaluation index and monitoring fuel economy of line 516

\begin{tabular}{|l|r|r|r|r|r|r|}
\hline Driver No. & Size & $\begin{array}{c}\text { Fuel } \\
\text { L/100km }\end{array}$ & $\mathrm{l}_{\mathrm{D}_{-} \mathrm{V}_{-} \mathrm{R}}$ & $\mathrm{l}_{\mathrm{D} 2 \mathrm{R}}$ & $\mathrm{l}_{\mathrm{D} 2 \mathrm{~V}}$ & $\mathrm{l}_{\mathrm{V} 2 \mathrm{R}}$ \\
\hline 516Driver 3 & 108 & 23.86 & 18.0 & 1.0 & 3.9 & 6.9 \\
\hline 516Driver 4 & 128 & 24.86 & 28.4 & 6.2 & 9.1 & 6.9 \\
\hline 516Driver 5 & 196 & 26.54 & 38.8 & 11.4 & 14.3 & 6.9 \\
\hline 516Driver 1 & 128 & 27.71 & 43.1 & 13.5 & 16.4 & 6.9 \\
\hline 516Driver 2 & 120 & 29.23 & 46.7 & 15.3 & 18.2 & 6.9 \\
\hline \multicolumn{2}{|l|}{ Spearman correlation } & 1 & 1 & 1 & - \\
\hline
\end{tabular}

\section{DISCUSSION}

Reducing fuel consumption is very important for bus companies. Appropriate arrangement of drivers, buses and routes is effective and convenient for bus companies. However, it is challenging to quantify driver-bus-route evaluation index.

Based on the Matching Rule of Driver-Bus-Route and bus transient fuel economy model, 5 key factors are abstracted to demonstrate driver-bus-route features. 6 statistical parameters are defined to describe features of drivers, buses and routes. The evaluation index of $l_{D 2 V}, l_{R 2 V}, l_{D 2 R}$ are defined to represent the evaluation rank of Driver-Bus, Route-Driver, Driver-Route.

Furthermore, the driver-bus-route evaluation index $\left(l_{D_{-} V_{-} R}\right)$ is proposed to estimate evaluation level of buses, drivers and routes. The results show that $\mathrm{l}_{\mathrm{D}_{-} \mathrm{V}_{-} \mathrm{R}}$ is Spearman correlated with fuel economy. The driver-busroute arrangement evaluation index can be sorted by . $\mathrm{l}_{\mathrm{D}_{-} \mathrm{V}_{-} \mathrm{R}}$. When the $l_{D_{-} V_{-} R}$ is small, the match of driver-bus-route tends to relatively better.

Compared with previous work by other researchers, this method is primarily based on driver habits, bus kinematical configurations, and route driving cycle features, and closely related to bus fuel consumption mechanism. It's an easy way for bus companies to sort better driver-bus-route arrangements to improve fuel economy and minimize cost for all bus lines.

\section{CONCLUSION}

Based on the bus fuel economy model and analysis of driver-bus-route features, some conclusions are as follow.

1) By the analysis of bus transient fuel consumption model, accelerator pedal percentage, acceleration pedal changing rate, gear selection, driving speed and driving acceleration are key factors for fuel economy.

2) The driver-bus-route evaluation index ( $\left.l_{D_{-} V_{-} R}\right)$ was proposed and the calculation method was illustrated in detail. The calibrated evaluation index can be used to predict driver-bus-route evaluation index of other bus line. It can be used to sort better driver-bus-route arrangements to improve fuel economy for bus companies.

3) The larger evaluation index l $\mathrm{D}_{-} \mathrm{V}_{-} \mathrm{R}$ demonstrated the higher fuel consumption, and vise versa.

\section{References:}

[1] M. Sivakand B. Schoettle, "Eco-driving: strategic, tactical, and operational decisions of the driver that improve vehicle fuel economy", Transportation Research Institute, 2011.

[2] E. Ericsson, "Independent driving pattern factors and their influence on fuel-use and exhaust emission factors," Transportation Research Part D: Transport and Environment,Vol. 6,No. 5, pp.325-345,2001.

[3] E. Ericsson, "Variability in urban driving patterns," Transportation Research Part D: Transport and Environment,Vol. 5,No. 5, pp.337-354,2000.

[4] K. Brundell-Freijand E. Ericsson, "Influence of street characteristics, driver category and car performance on urban driving patterns," Transportation Research Part D: Transport and Environment, Vol. 10,No. 3, pp.213-229,2005.

[5] Y. X. T. J. ZHU Wei-quan, "Effects analysis of external operating environment on the performance of bus routes by DEA and SFA," Journal of Jilin University, Vol. 43,No. 1,2013.

[6] D. Barnum, S. Tandonand S. McNeil, "Comparing the Performance of Bus Routes after Adjusting for the Environment Using Data Envelopment Analysis," Journal of Transportation Engineering,Vol. 134,No. 2, pp.77-85,2008.

[7] P. D. Siteand F. Filippi, "Bus service optimisation with fuel saving objective and various financial constraints," Transportation Research Part A: Policy and Practice,Vol. 35,No. 2, pp.157-176,2001.

[8] B. Yu, Z. Yangand X. Sun et al., "Parallel genetic algorithm in bus route headway optimization," APPLIED SOFT COMPUTING,Vol. 11, No. 8, pp.5081-5091,2011.

[9] W. Ruiand S. M. Lukic. "Review of driving conditions prediction and driving style recognition based control algorithms for hybrid electric vehicles". Vehicle Power and Propulsion Conference (VPPC), 2011 IEEE. 2011.

[10] Y. Nishiwaki, C. Miyajima, N. Kitaoka, K. Itouand K. B. I. Takeda. "Generation of pedal operation patterns of individual drivers in car-following for personalized cruise control". pp.1297-1301, 2007.

[11] T. Lee, B. Adornatoand Z. S. Filipi. "Synthesis of real-world driving cycles and their use for estimating PHEV energy consumption and charging opportunities: Case study for midwest/U.S", Institute of Electrical and Electronics Engineers Inc., pp.4153-4163, 2011.

[12] H. Ma, H. Xie, S. Chen, Y. Yanand D. Huang. "Effects of driver acceleration behavior on fuel consumption of city buses". Detroit, MI, United states: SAE International, 2014.

[13] B. Pengand S. L. Ma. "Analysis about Main Influence Factors of Vehicle's Fuel Consumption".pp. 941-945, 2013.

[14] A. Viswanathan, "Data driven analysis of usage and driving parameters that affect fuel consumption of heavy vehicles", Linköping university, 2013. 